\title{
Effects of Color Stimuli Application in Horticultural Therapy on the Changes in Challenging Behaviors of the Developmentally Disabled
}

\author{
Gae Suk Lee, Suk Young Yun*, Hyun Sug Choi, and Byung Jin Choi \\ Department of Horticulture, Daegu Catholic University, Gyeongsan 38430, South Korea
}

\begin{abstract}
The purpose of this study was to investigate the effects of applying color stimuli to a horticultural therapy program in an effort to analyze motivational factors of challenging behaviors of the developmentally disabled. Twelve subjects from residential facilities for the disabled attended total 15 sessions of programs, which utilized green plants and other materials with vivid colors such as sand, clay, paints, flowers, ribbons. The analyzing method was based on the Motivation Assessment Scale and a 16-item questionnaire was used to assess changes in the motivational factors of challenging behaviors at pre-, mid-, post-, and one month after the program. As a result, all motivational factors of attention, escape, tangible, and sensory factor changed significantly with $p=.013, .005$, .000 , and .008 respectively. For periodic comparison of effects, effects in changes of challenging behaviors became significant as the program advanced from mid- $(p=.046)$ to post- $(p=.003)$ program and lasted up to one month later $(p=.001)$. Horticultural therapy programs focused on color stimuli can provide positive changes to challenging behaviors of developmentally disabled.
\end{abstract}

Keywords: attention, developmental disorder, escape, sensory, tangible

\section{Introduction}

Among many types of disabilities, challenging behavior of persons with developmental disabilities is more difficult due to the nature of the disability. Persons with developmental disabilities often behave in a way that disrupts daily life such as physical and verbal aggression, self-injurious behavior, destructive behavior, stereotyped behavior, screaming and crying, which cause great stress and pain to not only themselves but also their families or service providers (Kim et al., 2018). Challenging behavior indicates abnormal behavior along with the terms such as problem behavior, hyperactivity, and conduct disorder to refer to cases in which persons with developmental disabilities do harm to themselves or others (Kim et al., 2015).

Challenging behavior is defined in various ways, and these definitions are important in clarifying what challenging behavior is and how to establish intervention methods for such behavior. Approach to maladaptive behavior in Korea mostly adopts behavior modification that focuses on directly reducing or eliminating the behavior with attention in the behavior itself (Lee and Yang, 2001). This method seems to have temporary effect but it merely intends to eliminate the

Received: July 17, 2018, Revised: August 1, 2018, Accepted: August 2, 2018

First author: Gae Suk Lee, E-mail: gae-suk-e@ @anmail.net, ORCID: 0000-0002-2847-6700

*Corresponding author: Suk Young Yun, E-mail: yune1004@cu.ac.kr, ORCID: 0000-0002-5862-0021 
behavior itself without understanding the cause of such maladaptive behavior, thereby possibly causing negative interaction between instructor and children with disabilities, resulting in relapse, and difficult to generalize the results. Therefore, there was a need for intervention that can more fundamentally change the behavior (Lee and Kim, 2005).

Colors have effect on stimulating people's emotions through previous studies or daily life experiences (Kim, 2012). As a result of analyzing how colors affect children with developmental disabilities, Choi (2008) reported that for children with developmental disabilities that are limited in expressing their will, colors express and stimulate their emotions, and color stimulus, which are caused when choosing the color, stimulate the brains and bring free expression and psychological stability to children with developmental disabilities with repressed emotions. Meanwhile, recent studies are extensively applying horticultural therapy to bring behavioral changes to persons with developmental disabilities (Seo et al., 2000). Jung and Sainato (2006) studied the positive effects of horticultural therapy on changes in challenging behavior of persons with developmental disabilities, and claimed that horticultural activities through gardening affect sociability development of children with autism. Ann (2004) reported that horticultural therapy using social reinforcement reduces autistic tendency of students with autism as well as motives and frequency of problem behaviors.

Therefore, to determine the effects of color stimulus application in horticultural therapy on changes in challenging behavior of persons with developmental disabilities, this study first conducted analysis on each factor of motivation assessment, and determined the effects on factors of challenging behavior of persons with developmental disabilities such as sensory, escape, attention, and tangible.

\section{Research Methods}

\section{Design}

This study is a single time series design performing four evaluations before, during, after and one month after the program using the motivation assessment scale (MAS) of challenging behavior. The baseline was evaluated using direct observation and motivation assessment scale before the horticultural therapy program, and the effectiveness of the program was determined through the test during the program (HTP Session 8) and right after. To determine the persistence of the effectiveness of the program, the same test was conducted one month after the program to compare the assessment result with the baseline result.

\section{Subjects}

\section{Selection criteria of subjects}

The subjects of this study were persons with developmental disabilities in S Facility for Persons with Disabilities located in B City, and the selection criteria for 12 persons with developmental disabilities are (1) registered persons with disabilities aged 20 or older, (2) adults with severe disabilities diagnosed as persons with developmental disabilities by the Welfare of Disabled Persons Act (Class 1, Class 2 or redundant), (3) those who have no limitation of vision, (4) those who obtained consent of participation by themselves or guardians, and (5) those with clear challenging behavior.

\section{General characteristics of subjects}

The subjects were seven male and five female adults with developmental disabilities living in S Facility for Persons with Disabilities located in B City with the mean age of $42.75 \pm 8.75$. The average length of residence at the facility was 8 years and 2 months, and five of them were persons with autistic disorders and seven with intellectual disabilities. 


\section{Tools}

\section{Color stimuli application}

If one feels certain emotions when looking at a color, those emotions lead to physical responses and ultimately reflected on specific behavior. Active and provocative red and yellow bring energy to the mood and blue, purple and green tend to calm down the mood (Birren, 2003). Therefore, this study used the green color of plants as well as vivid colors of sand, clay, pressed flowers and stones as the key materials of color stimulus. Paints of red, yellow, green and blue are used in dyeing, after which the subjects made name tags using dry roses and baby's breaths plants, and made terrariums using various colors of sand. In addition, they made bouquets using vivid tone ribbons, and played color games at a field trip to a rose festival. The horticultural therapy with color stimulus consisted of total 15 sessions (Table 1).

\section{Implementation method}

The motivation assessment scale (MAS) of challenging behavior established preventive strategies of each factor maintaining challenging behavior and considered appropriate methods of support (Kim et al., 2015). Preventive strategies such as motivation factors of attention, escape, tangible and sensory are as follows. First, if the motivation factor of challenging behavior is "attention," compliments were used adequately for reinforcement, and the compliments were provided actively in performing given roles within the program for immediate reinforcement. Second, if the motivation factor of challenging behavior was "escape," the opportunity of selection was provided, and the opportunity for material selection of color they want were expanded and provided to induce attention in the activity. Third, if the motivation factor of challenging behavior was "tangible," the subject were provided with objects and activities they preferred when they did not conduct challenging behavior, thereby lowering the frequency of activity. Fourth, if the motivation factor of challenging behavior was "sensory," the subject found the preferred object and activity to enjoy leisure time themselves (Fig. 1).

Table 1. Contents of color stimulation horticultural therapy program

\begin{tabular}{|c|c|c|c|}
\hline Session & Program & Key material for color stimulation & Color \\
\hline 1 & Making a name card & Pressed flowers & Red, yellow, green, blue \\
\hline 2 & Making a terrarium & Colored sand & Red, yellow, green, blue \\
\hline 3 & Making a mini frame & Pressed flowers & Red, yellow, green, blue \\
\hline 4 & Making a dish garden & Succulents, colored sand, ribbon & Pink, yellow, green, white \\
\hline 5 & Making a rubber boot planter & Rubber shoes (white, yellow, blue), succulents & Yellow, green, white, blue \\
\hline 6 & Hydroponic farming & Purple onions, purple sweet potatoes, plastic cups, ribbon & Yellow, green, blue, red, purple \\
\hline 7 & Water culture & Dracaena sandercana, colored sand, plastic cups, ribbon & Yellow, green, blue, white \\
\hline 8 & Making a grass doll & Zoysia japonica, plastic cups, wire, ribbon & Red, green, white \\
\hline 9 & Making a vegetable sandwich & Sprouts, bread, blueberry jam & Green, white, purple \\
\hline 10 & Making sachet bags & fabric bags, ribbon & Red, purple, pink, green, blue \\
\hline 11 & Making a corsage & Dianthus caryophyllus, wire, ribbon, & Pink, red, white, green \\
\hline 12 & Making a flower basket & Dianthus caryophyllus, wrapping, ribbon & Green, pink, white \\
\hline 13 & Participating in a rose festival & Rosa hybrida & Red, green, white \\
\hline 14 & Making a rose bouquet & Rosa hybrida, ribbon, floral tape & Red, green, pink, white \\
\hline 15 & Making a canapé & Biscuit, cheese, cherry, blueberry & Green, red, purple, white \\
\hline
\end{tabular}


Figure 1. Prevention strategies by motivational factors.

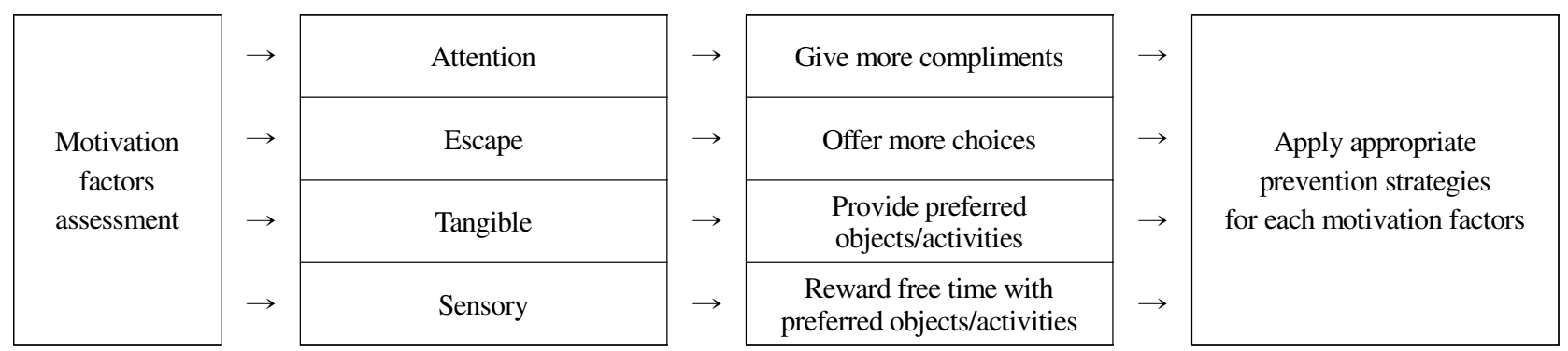

\section{Assessment tool}

The challenging behavior MAS devised by Durand and Crimmins (1988), which is the tool to determine the situations in which people are likely to behave in certain ways, was used for this study. The behavior was rated on a scale from 0 to 6 points, with the score higher with higher ratio of variables for determining the function and motive of challenging behavior. By completing the scale, 16 precedent conditions were evaluated whether specific challenging behavior appears, and 12 subjects were assessed.

\section{Data analysis}

Data assessed before, during, after and one month after the horticultural therapy program satisfied sphericity assumption using IBM SPSS 19.0 Program ( $p=.175)$, and thus repeated measures ANOVA was conducted to analyze the changes in the subjects according to the process of the program.

\section{Results and Discussion}

\section{Challenging behavior of subjects and MAS results}

To determine the effects of horticultural therapy using color stimulus on changes in challenging behavior of persons with developmental disabilities, this study determined the motivation of challenging behavior and implemented suitable programs of each factor. From the contents of specified challenging behavior by 12 subjects with developmental disabilities, behaviors that make others comfortable were spitting, hitting others, knocking things over, pushing and losing temper, and behaviors that harass oneself were hurting, sensitive response and anxiety, hitting one's face, and shaking body. The results of MAS show three persons were categorized as sensory, three as tangible, two as escape, three as attention, and one as escape and tangible (Table 2).

\section{Changes in challenging behavior}

\section{Overall change in each factor of motivation assessment}

This study is to determine the effects of color stimulation in horticultural therapy on changes in challenging behavior of persons with developmental disabilities. MAS was used and changes were measured and analyzed with four sub-factors (sensory, escape, attention and tangible) in order to examine changes before, during, after and one month after horticultural therapy. Scores of each factor showed significant results in variables of attention ( $p=.013)$, escape $(p=.005)$, tangible ( $p=.000)$, and sensory ( $p=.008)$. Overall, there were significant changes ( $p=.000)$ in terms of period (pre-, mid-, post-, and 
Table 2. Contents of color stimulation horticultural therapy program

\begin{tabular}{cccc}
\hline Subject & Type of challenging behavior & A challenging target action & Assessment result \\
\hline A & Spitting, hitting others, sulking & Spitting & Attention \\
B & Picking skin, clapping, body shaking & Picking skin & Escape \\
\hline C & Shouting, anger, tearing clothes & Shouting & Sensory \\
\hline D & Picking skin, eating things that aren't food & Picking skin & Tangible \\
E & Hitting others, refusal to comply & Hitting others & Escape, Tangible \\
\hline F & Crying out loud, throwing objects & Throwing objects & Sensory \\
\hline G & Hitting others, making excuses & Making excuses & Escape \\
\hline H & Sensitive responses, anxious behavior & Sensitive responses & Attention \\
\hline I & Anger, sulking & Sulking & Attention \\
\hline J & Anger, hitting others & Anger & Tangible \\
K & Slapping self, repetitive language & Slapping self & Tangible \\
\hline L & Nail biting, kleptomania & Nail biting & Sensory \\
\hline
\end{tabular}

Table 3. Pre-, Mid-, Post-, and one month after program evaluation in challenging behavior by motivational factors of the subjects

\begin{tabular}{|c|c|c|c|c|c|c|}
\hline Item & Pre & Mid & Post & One month after & $\mathrm{F}$ & $p$ \\
\hline Attention & $12.7 \pm 5.8^{\mathrm{z}}$ & $12.3 \pm 5.1$ & $11.6 \pm 5.0$ & $12.1 \pm 5.1$ & 4.163 & $.013^{*}$ \\
\hline Escape & $12.3 \pm 3.5$ & $12.0 \pm 3.7$ & $11.4 \pm 3.2$ & $11.3 \pm 2.9$ & 5.126 & $.005^{* *}$ \\
\hline Tangible & $15.9 \pm 2.3$ & $15.1 \pm 1.9$ & $11.6 \pm 1.7$ & $14.6 \pm 2.3$ & 10.661 & $.000^{* * *}$ \\
\hline Sensory & $12.3 \pm 4.3$ & $11.5 \pm 3.8$ & $11.4 \pm 3.8$ & $11.5 \pm 3.8$ & 4.721 & $.008^{* *}$ \\
\hline Total & $53.2 \pm 6.4$ & $50.9 \pm 5.6$ & $49.0 \pm 5.8$ & $49.7 \pm 6.2$ & 12.037 & $.000^{* * * *}$ \\
\hline
\end{tabular}

${ }^{\mathrm{z}}$ Mean \pm standard deviation

Significant at ${ }^{*} p<.05,{ }^{* *} p<.01,{ }^{* * *} p<.001$ by repeated measures design ANOVA test.

one month after post program) and motivation assessment factors. In particular, in the assessment after one month to determine the persistence of effect, the effect remained at the level of change assessed during the program (Table 3).

\section{Comparison by period of challenging behavior}

Analysis on changes in each period of challenging behavior showed that pre- to mid- program ( $p=.046)$, to post( $p=.003$ ), and to one month after ( $p=.001)$ the assessment showed significant results, which proved that the program was effective. Meanwhile, the assessment mid- to post-program, mid- to one month after program, post- to one month after the program showed results that are not significant. However, compared to before the horticultural therapy program, the effectiveness turned out to be maintained (Table 4).

In summary of the results, color stimulus application in the horticultural therapy program had a highly positive effect on changes in motivation factors (attention, escape, tangible, sensory) of challenging behavior of persons with developmental disabilities and also had significant effects on frequency of challenging behavior. This is consistent with the result in the study on children's psychological therapy program using color therapy that remarkably reduced the intensity or frequency of problem behavior (Yang, 2010). 
Table 4. Changes by period of challenging behavior

\begin{tabular}{llll}
\hline Period & $\mathrm{MD}^{\mathrm{z}}$ & $\mathrm{SD}^{\mathrm{y}}$ & $p$ \\
\hline Pre - Middle & 2.292 & .703 & $.046^{*}$ \\
Pre - Post & 4.167 & .867 & $.003^{* *}$ \\
Pre - One month after & 3.542 & .865 & $.001^{* *}$ \\
Middle - Post & 1.875 & .723 & $.150^{\mathrm{NS}}$ \\
Middle - One month after & 1.250 & .822 & $.940^{\mathrm{NS}}$ \\
Post - One month after & -1.875 & .723 & $.150^{\mathrm{NS}}$ \\
\hline
\end{tabular}

${ }^{\mathrm{z}}$ Mean difference value, ${ }^{\mathrm{y}}$ Standard deviation.

${ }^{\mathrm{NS}}$ Non significant or significant at ${ }^{*} p<.05,{ }^{* * *} p<.01$ by repeated measures design ANOVA test

Meanwhile, the result of Kim (2004) showed that children with emotional disturbance are much more impulsive and lack concentration than general children, and show sudden behavioral changes. Thus, the results of this study support that it is desirable to apply colors that can provide psychological stability and relieve tension, and that green colors can purify person's thoughts and emotions effectively.

\section{Conclusion}

This study was conducted to determine how various colors of horticultural therapy program are effective for changes in motivation of challenging behavior by persons with developmental disabilities, targeting those among persons in the $\mathrm{S}$ Facility for Persons with Disabilities located in B City. The horticultural therapy program was conducted from February 3 to June 30, 2016, and February was for collection of information and section of subjects to prepare in advance to review various records of the subjects. Twelve subjects that can be observed with clear expressions of challenging behavior were selected, and the MAS of challenging behavior was used to determine the motivation factors, applying preventive strategies of motivation factor. The attention factor of challenging behavior $(p=.013)$, escape $(p=.005)$, tangible $(p=.000)$, and sensory ( $p=.008)$ showed significant results. There was a significant change at mid- $(p=.046)$ and post- $(p=.003)$ program from pre- in comparison of sessions in motivation assessment, and the result continued to persist with significance after one month $(p=.001)$.

\section{References}

Ann, H.S. 2004. Effect of horticultural therapy applied by social reinforcement on the reduction of problem behaviors in students with autistic disorder. Master's thesis, Konkuk University, Seoul, Korea.

Birren, F. 2003. Color psychology and color therapy: A factual study of the influence of color on human life (H.J. Kim, Trans.). Paju, Korea: Dongguk Publishing Co. (Original work published 1950)

Choi, H.S. 2008. A study on the use of color in paintings drawn by children with developmental disorder. Master's thesis, Kyonggi University, Suwon, Korea.

Durand, V.M. and D.B. Crimmins. 1988. Identifying the variables maintaining self-injurious behavior. J. Autism Dev. Disord. 18(1):99-117.

Jung, S.H. and D.M. Sainato. 2006. Using high-probability request sequences to promote functional and adaptive skills in young children with special needs. Korean J. Spec. Educ. 41(2):21-44.

Kim, M.O., G.E. Kim, and M.A. Jung. 2018. The effect of support environment in service agencies on the challenging behavior support for people with developmental disabilities. J. Disabil. Welf. 40:237-262. 
Kim, M.O., Y.D. Kim, D.G. Kim, J.Y. Yu, and E.S. Lee. 2015. Development of performance indicators for allocation -Societies without discrimination and abuse- (Report No. 10). Seoul, Korea: Community Chest of Korea.

Kim, N.R. 2012. A study on the mood states through color stimulus of indoor landscape plants. Master's thesis, Kyungsung University, Busan, Korea.

Kim, N.Y. 2004. A research on the color preference of emotionally disturbed children and a study on an effective learning environment. Master's thesis, Sookmyung Women's University, Seoul, Korea.

Lee, H.S. and H.S. Kim. 2005. The effect of behavior support through functional analysis on young children with developmental delays displaying maladaptive behaviors. Korean J. Spec. Educ. 40(1):91-111.

Lee, M.K. and M.H. Yang. 2001. The effects of choice of preferred activities on adaptive behaviors of children with developmental delay included in the regular kindergarten. J. Emot. Behav. Disord. 17(1):329-353. Retrieved from http://www.ksebd.org/home/

Seo, J.G., J.S. Lee, B.H. Gwack, H.R. Gwack, and A.G. Lee. 2000. Horticultural Therapy. Seoul, Korea: Dankook University Press.

Yang, H.J. 2010. A study on psychological therapy program for children based on color therapy. Master's thesis, Seoul National University of Education, Seoul, Korea. 
